\title{
Effectiveness of ABCN Interventions on Reducing Under Two Child Malnutrition in a Selected NNP Area
}

\author{
M. A. Hossain ${ }^{1} *$ Naimunnahar $^{2}$ and Bhuyan M.A.H. ${ }^{3}$ \\ Plan Bangladesh $^{1}$, National College of Home Economics ${ }^{2}$ \\ Institute of Nutrition and Food Science, University of Dhaka ${ }^{3}$
}

\begin{abstract}
:
This cross-sectional comparative study was conducted in Muradnagar Upazila, Comilla district to see the effectiveness of NNP-ABCN (Area Based Community Nutrition) interventions on reducing under-two child malnutrition (0-23 months) and establish whether there is any significant difference from the non-operational area. A total of 240 households, of which 120 were from the NNP project area with children aged between 0-23 months were randomly selected. In households with more than one child at this age category, the last child was selected. Indices of nutritional status that is weight-for-age, length-for-age and weight-for-length were computed for the measurement of nutritional status. Analysis of nutritional status data show that the prevalence of underweight $(<-2 \mathrm{SD})$ in the project area (35.8\%) was slightly lower than the non-project area (39.2\%) with severe underweight being $5.0 \%$ vs. $7.5 \%$ respectively. Within the project sample, $32.5 \%$ children were stunted (<-2SD) with $11.7 \%$ being severely stunted while in non-project area these figures were $33.3 \%$ and $7.5 \%$ respectively. On the other hand, $17.5 \%$ children were wasted (<-2SD) with $2.5 \%$ being severely wasted in project area while in nonproject area these figures were $19.2 \%$ \& $1.7 \%$ respectively. No significant differences in the prevalence of stunting, wasting and underweight $(<-2 \mathrm{SD})$ between the project area and non-project area (WAZ, p=0.078; LAZ, p=0.214 \& WLZ, $p=0.421$ ) were found. The study area and sample size aren't large enough to draw any conclusion still this is an indication that NNP-ABCN interventions may not be effective in reducing under two child malnutrition in study area. Even though NNP has been involved in providing ABCN interventions in the project area, there is still need for more targeted and income oriented nutrition interventions in the project area. Large scale operational research is thus suggested to adopt those findings for the whole NNP areas.
\end{abstract}

Key Words:

Under-two child, Nutritional status, Wasting, Stunting, Underweight, ABCN

Bangladesh Journal of Nutrition. Vol. 24-25 December, 2011-2012. Institute of Nutrition and Food Science, University of Dhaka, Dhaka-1000, Bangladesh.

* Author for Correspondence 


\section{Introduction:}

Nutrition is the basis for a healthy life, a healthy family, a healthy community, and a healthy country. However, for 840 million people worldwide, adequate nutrition is an unattainable luxury. Malnutrition is a factor in over half of child deaths in the world and is a multifaceted issue spanning all aspects of life. South Asia alone is home to $50 \%$ of the malnourished children in the world. Even more startling is the fact that half of the malnourished children in the developing world are concentrated in only three countries: India, China, and Bangladesh ${ }^{1}$.

Child malnutrition is the most widely spread disorder in tropical and subtropical areas $^{1}$. It is not a simple matter of whether one has satisfied one's appetite or not since a child who eats enough to satisfy immediate hunger can still be malnourished ${ }^{2}$. Malnutrition has been recognized as a consequence of poverty and is known to cause a great deal of both physical and emotional human suffering while it is viewed in the context of violation of child's human rights ${ }^{2,3}$.

Causes of malnutrition are complex, multidimensional and interrelated - many of which are the results of problems at the community and household level. In children, malnutrition is most likely to strike those who lack nutritionally adequate diets, are not protected from frequent illnesses and do not receive adequate care $^{2}$. A malnourished family often lacks knowledge of proper nutrition and food security in their household. They may also not have access to health services or live in a healthy environment. In Bangladesh, the lack of one or more of these aspects, as well as problems with coordinating government ministries, result in some of the highest rates of malnutrition in the world, as stated in the Program Implementation Plan for the National Nutrition Project ${ }^{4}$. It is through a combination of nutritional education, resources, and well-targeted care that a community is able to battle malnut rition.

The nutritional status of infants and children under two years of age is of particular concern since the early years of life are crucial for optimal growth and development $^{5}$. Their nutritional well-being reflects household, community and national investments in family health thereby contributing both directly and indirectly to overall country development and in particular, development of human resource $^{6}$. It is reliably estimated that, globally 226 million children below 5 years old are stunted, 67 million are wasted and 183 million weigh less than they should for their age $\mathrm{e}^{2}$. In Bangladesh, about $43 \%$ of pre school age children are stunted and $17 \%$ severely stunted, $13 \%$ of them are wasted and $1 \%$ severely wasted and $48 \%$ of them are underweight, with $13 \%$ severely underweight ${ }^{7}$. 
Rates of child malnutrition rise very rapidly from 6 months of age and reach their peak among weaning age children (6 to 23 months of age) who are nutritionally most vulnerable. The NNP baseline survey 2004 estimated value of stunting is $36.1 \%$, underweight $40.6 \%$ and wasting $13.5 \%$. According to child and maternal nutrition survey of Bangladesh 2005, the prevalence of stunting of under two children is $34.5 \%$, underweight $35.9 \%$ and wasted $19.8 \%{ }^{8}$.

Through a successful nutrition program, this high rate of child malnutrition can be lowered in Bangladesh. As the Food and Agriculture Organization of the United Nations (FAO) says, through improving the nutrition of the nation, lives can be saved and people are given the opportunity for physical and mental development ${ }^{9}$. In the past sixteen years, UNICEF has revolutionized nutrition programs worldwide through their emphasis on community-based nutrition programs which target the specific causes of malnutrition at the household level ${ }^{10}$.

Various community-based nutrition programs have been conducted since the last fifteen years both in small scale and large scale but the questions have been arouse repeatedly regarding their effectiveness. Community-based activities aimed at changing care practices and improving the nutritional status of children requires substantial resources in form of time and funds. Since this involves partnerships: communities, government, non-governmental organizations and other stakeholders have been involved in intervention projects within the rural and urban poor areas of this country to maximize the quality of human life ${ }^{6}$.

National Nutrition Program (NNP) is one of the governmental organizations that are involved in various activities aimed at implementing the Programs related to Health \& Nutrition issues as nutrition sub sector in Health, Nutrition and Population Sector Program (HNPSP) under the Ministry of Health and Family Welfare since July 2004. The overall objective of NNP is to achieve a sustainable improvement in birth weight and nutritional status of vulnerable groups (women $\&$ children) through adoption of behavioral changes and proper utilization of health care system by individuals and households involving local communities ${ }^{4}$.

BINP, the predecessor of NNP, is considered a successful program as a whole with little controversies regarding the strength of impact study design, no impact studies had been done regarding the effectiveness of ABCN interventions of NNP phase -1 on the under two target groups except one mid-term evaluation study. Out of this concern, a nutritional assessment to determine the nutritional status of children 023 months in the NNP project area of Comilla district was conducted and compared with the non-project area to establish whether there is any significant difference in the nutritional status of children in the two groups. 


\section{Materials and Methods:}

\section{Study Area:}

A comparative cross-sectional study was carried out between June and July 2008 in Comilla district. The district has thirteen Upazilas. NNP has activites in three Upazilas namely: Muradnagar, Chandina and Laksham. Households within the Muradnagar Upazila, a NNP project area and with children aged between 0-23 months were compared with those outside the project area but within the same district. Six CNCs from six villages of three unions of Muradnagar Upazila and two control villages of Homna Upazila were compared for the study purpose. The project area was selected purposively with a non randomized control group.

\section{Sampling Technique:}

According to the Child and Maternal Nutrition Survey (CMNS) 2005 by HKI, the prevalence of under 2 chronic malnutrition (underweight) is $9.2 \%{ }^{(10)}$; This assumption and a confidence interval (CI) of 95\% were taken into account for sample size determination. Using the statistical formula for comparative studies, a sample size of 240 households was used.

The study design is a multistage sampling design with stages of selection at the following levels: Upazila, union, village and CNC. The Muradnagar Upazila of Comilla district was selected purposively. Three of the twenty one unions of Muradnagar were randomly selected using simple random selection. One village (total 6 villages) from three unions was selected randomly using simple random selection. Then one CNC from each of these villages was selected randomly. Finally total samples were distributed equally among the CNCs and the sapling units were drawn from these CNCs using systematic random sampling technique. For the control sample, 50\% of the total samples was selected and surveyed from the same category and having the same socio-economic \& cultural characteristics as the project households have. Then a union from that Upazila and two villages from that union were selected randomly.

\section{Data Collection:}

A structured questionnaire was used in the study to collect information on Socio economic condition of the households and on ABCN services provided by NNP. A form in the structured questionnaire was used to record information on anthropometric measurements (weight and length).Their corresponding deviation scores (Z-scores) were calculated with reference to the National Centre for Health Statistics (NCHS) population, using the cut-off points recommended by the World 
Health Organization. The weight was recorded to the nearest $0.5 \mathrm{~kg}$. An wooden measuring board was used to take the children's supine length.

\section{Data analysis:}

Anthropometric data analysis was carried out by using anthro (NCHS/WHO) program to convert raw anthropometric data (weight and length) into nutritional indicators (Weight-for-Age $\{\mathrm{WAZ}\}$, Length-for-Age $\{\mathrm{LAZ}\}$, and Weight-forLength $\{\mathrm{WLZ}\}$ ) and compare them with the National Centre for Health Statistics (NCHS) reference figures. The data were analyzed by using SPSS PC version 10 to observe means, distributions and tests of significance.

Project households interviewed were compared with the control households for all observed characteristics and outcomes. Group means were tested by using independent sample t-test $(\mathrm{p}<0.05)$, and the prevalence of different indicators between two groups was tested using Pearson Chi-square $(p<0.05)$. The results were presented mostly in tabular form and using graphical illustrations in some cases.

\section{Results:}

\section{Socioeconomic Data of Households}

Table 1 shows the average composition of respondents by selected background characteristics. Tests of statistical significance showed that the two groups were similar in the socio-economic characteristics. The observed household size ranged from 3-22 persons.

The education levels of the respondents were essentially the same in both the project and non project areas. Nearly one third (30.8 percent) of the respondents in the project area had no education compared with 35.0 percent in control area. In contrast, 32.6 percent of the respondents in project area reported having under secondary education, while this proportion was higher in control area (45.0 percent). On the other hand, 36.6 percent of the respondents reported having had a secondary education or above, while this figure was 20.0 percent in control area. It is thus evident that, in terms of women's education, project area was highest and control area was lowest but the difference was not significant $(p>0.05)$. Casual labor was found to be the major source of income for slightly more than half of the households in both the project area (55\%) and non-project area (58.8\%). A significance difference $(\mathrm{p}=0.037\}$ was observed between project and control households by cultivable land ownership status $(\mathrm{p}>0.05)$. 


\section{Assessment of malnutrition:}

Proportion of under two children found to be underweight for their height, or wasted in the study are shown in Table 2 and Chart 1. In the project sample, 17.5 percent of all under two children were underweight for their height, or wasted (<2SD) with 2.5 percent being severely wasted while in control area these figures were $19.2 \& 1.7$ percent respectively. Within the project sample, 32.5 percent of the children were short for their age, or stunted (<-2SD) with 11.7 percent being severely stunted while in control area these figures were 33.3 with 7.5 percent. Within the project sample, 35.8 percent of the children were underweight for their age (<-2SD) with 13.3 percent being severely underweight while in control area these figures were 39.2 with 11.7 percent. Using Pearson Chi-square test, the project and control households differ insignificantly in respect of weight for age $\left(\lambda^{2}=5.112, p=0.078\right)$, length for age $\left(\lambda^{2}=3.087, p=0.214\right)$ and weight for length indicator $\left(\lambda^{2}=1.731, \mathrm{p}=0.421\right)$.

\section{Exclusive Breastfeeding and Complementary Feeding:}

Children should be exclusively breastfed until the age of six months. In this study, a child of age $0-23$ months of age who was breastfed or still being breastfed for five or six months of age was considered to be exclusively breastfed and beginning of sixth month or seventh month was considered the ideal time for introduction of complementary foods.

Proportion of children who were still exclusively breastfed before six month of age in project area was 23.3 percent and in control area 12.5 percent and the proportion who were breastfed continually upto two years was 73.3 percent in project area and 72.5 percent in control area. About 96.0 percent of the women fed colostrum to their last child in project area and it was 86.7 percent in control area. Among the mothers of children aged over six months, practice of exclusive breastfeeding for 56 months and introduction of complementary feeding at 6-7 months was 37.5 percent in project area and 32.5 percent in control area.(Table 3). Pearson Chisquare test shows that the respondents between project and control households differed significantly $\left(\lambda^{2}=10.121, \mathrm{p}=0.018\right)$.

In contrast proportion of mothers of children 0-23 months who had knowledge regarding exclusive breastfeeding for 5-6 months period and introduction of complementary feeding at 6-7 months was 81.7 percent in project area and 63.3 percent in control area. Using Pearson Chi-square test, the project and control households differ significantly $\left(\lambda^{2}=25.514, \mathrm{p}=0.000\right)$ by knowledge about duration of exclusive breastfeeding and introduction of complementary feeding to their last 
child. It clearly indicates a large hiatus between practice and knowledge both in project and control area and between project and control area. On the other hand almost all of the mothers (95.8\% in project \& $86.7 \%$ in control) fed colostrum to their children knowing the importance of feeding colostrum $(97.5 \%$ in project \& $94.2 \%$ in control). A significant proportion of the respondents held belief in feeding continually to the male child for two and half years and female child for two years. Considering their belief, 65.8 percent of the project mothers said that children should continually breast fed for minimum two years while in control area it was 37.5 percent (Table 4 ).

\section{Children's Dietary Diversity:}

The extent of children's dietary diversity found in a household was assessed by asking the respondents about the food groups the child had consumed the day before the study. Table 5 shows the percentages of children found to be consuming a specific food group. Cereals \& roots/tubers were the most common food group consumed by children in the project and control household. The next most commonly food groups were milk/milk products (35.8 vs. 60.0 percent), followed by pulses/legumes/nuts (38.3 vs. 40.0 percent), fruits or vegetables (22.5 vs. 20.0 percent) and meat/poultry/fish (22.5 vs. 17.5 percent). There were marked variations in the consumption of vitamin A rich plant foods (28.3 vs. 7.5 percent), eggs ( 47.5 vs. 12.5 percent) and foods cooked in oils or fats ( 46.7 vs. 32.3 percent) between project and control subjects respectively.

\section{Discussion and Conclusion:}

In respect of breast feeding and complementary feeding practices, mothers in project households fed more exclusively for 5-6 months and initiated complementary feeding to their last child at right time of $6-7$ months of age (48.9\% vs. $37.1 \%$ in control) which differ less significantly $(\mathrm{p}<0.05)$. In contrast proportion of knowledge regarding exclusive breastfeeding and introduction of complementary feeding at right time was found 81.7 percent in project area and 63.3 percent in control area which differ significantly $(\mathrm{p}<0.01)$. It clearly indicates a large hiatus between practice and knowledge both in project and control area and between project and control area. In different studies exclusive breastfeeding was found $49.3 \%$ at 4 months by Huq et al, $69 \%$ at 6 months by Islam, 55\% at 6 months by Nasirullah, $12.2 \%$ at 4 months by Talukder. But in this study, beyond the statistical findings, it was observed that most of the respondents had no clear idea about what is actually called exclusive breastfeeding and complementary feeding. They often fluttered about it which was reflected in their practices and knowledge. 
Through nutrition education the attitude can be reversed, Pediatricians, Obstetricians, nutritionists and other health personnel should play the pioneer role while motivating mothers to practice exclusive breastfeeding and complementary feeding.

It was also observed that majority of the children's diet was not diversified both in project and control areas (64\% vs. $74 \%$ respectively). These mean households did not learn how to use the foods they were secured with in the first place. The percentage of households consuming vitamin A richer foods, eggs from poultry and foods cooked in some extra oil were differed to some extent but not in a significant fashion. So strengthening the nutrition gardening component of NNP may be the solution that will enable households to consume more micronutrient rich foods, to diversify their children's diet and thereby to increase the quality of diet. Attention should be given to the hygienic aspects of food and also to food handler and consumer of foods to ensure proper utilization of foods consumed.

The prevalence of stunting, wasting and underweight in project and control area was not differed significantly ( $\mathrm{p}>0.05$ ). In project area, 32.5 percent of the children were short for their age, or stunted (<-2SD) with 11.7 percent being severely stunted in contrast to 33.3 with 7.5 percent in control area respectively while 17.5 percent of all under two children were underweight for their height, or wasted (<2SD) with 2.5 percent being severely wasted in project area in contrast to 19.2 \& 1.7 percent respectively in control area. In project area 35.8 percent of the children were underweight for their age (<-2SD) with 13.3 percent being severely underweight while in control area these figures were 39.2 with 11.7 percent respectively. So questions arise regarding the effectiveness of $\mathrm{ABCN}$ interventions on reducing under two child malnutrition. Further investigation needs to find out the factors responsible for the parallel trends of the indicators measured both in project and non-project areas.

Innovative approaches should be developed instead of traditional system so that the households can adopt it easily and effectively and change their behaviour thus increasing the sustainability of the interventions provided and improve the program effectiveness that will leave a more sustainable impact on reducing under two child malnutrition. Nonetheless, this is a small scale study enough to draw any strong conclusion regarding the whole NNP. Still it can be said from the study findings that if some income-generating activities are implemented alongside nutrition gardening, the key problem above mentioned can be remedied. Large scale operational research is thus suggested to adopt those findings for the whole NNP areas. 
Tables and Chart:

Table 1: Distribution of households by selected socio-economic characteristics in the project and non-project area.

\begin{tabular}{|c|c|c|c|}
\hline Characteristics & $\begin{array}{c}\text { Project area } \\
\quad \mathrm{N}=120\end{array}$ & $\begin{array}{c}\text { Non-project } \\
\text { area } \\
\mathrm{N}=120\end{array}$ & $\begin{array}{c}\text { Statistical } \\
\text { Significanc } \\
\text { e }\end{array}$ \\
\hline \multicolumn{4}{|l|}{ Household composition } \\
\hline Mean mothers age & $25.0 \pm 6.1$ & $24.7 \pm 6.0$ & NS** \\
\hline Mean children's age & $11.2 \pm 6.6$ & $11.5 \pm 6.7$ & NS** \\
\hline Family size (average) & $6.6 \pm 3.31$ & $6.8 \pm 3.33$ & NS** \\
\hline \multicolumn{4}{|l|}{ Mother's educational status } \\
\hline No education & $30.8(37)$ & $35.0(42)$ & NS* \\
\hline Primary incomplete & $10.1(12)$ & $22.5(27)$ & NS* \\
\hline Primary complete & $22.5(27)$ & $22.5(27)$ & NS* \\
\hline Secondary and above & $36.6(44)$ & $20.0(24)$ & NS* \\
\hline \multicolumn{4}{|l|}{ Economic status } \\
\hline Average income (Tk.) & $\begin{array}{c}8500.00 \pm 4801.2 \\
6\end{array}$ & $\begin{array}{c}7133.33 \pm 3032.5 \\
5\end{array}$ & NS** \\
\hline Average expenditure (Tk.) & $\begin{array}{c}7300.00 \pm 3239.9 \\
8\end{array}$ & $\begin{array}{c}7133.33 \pm 3032.5 \\
5\end{array}$ & NS** \\
\hline $\begin{array}{l}\text { Average expenditure on food } \\
\text { (Tk.) }\end{array}$ & $\begin{array}{c}5002.50 \pm 1940.3 \\
1\end{array}$ & $\begin{array}{c}4962.50 \pm 1896.6 \\
6\end{array}$ & NS** \\
\hline $\begin{array}{l}\text { Average cultivable land } \\
\text { Ownership (dcl.) }\end{array}$ & $91.1 \pm 78.7$ & $117.3 \pm 83.1$ & $(\mathrm{P}<0.05)^{* *}$ \\
\hline
\end{tabular}

Notes: In brackets- frequency; NS - not significant at $p$ value $<0.05{ }^{*}$ Chi-square test $* *$ t-test 
Bangladesh J. Nutr. Vol. 24-25 Dec 2011-2012

Table 2: Distribution of children 0-23 month's age, percentage classified as malnourished according to three indices of anthropometric status by area.

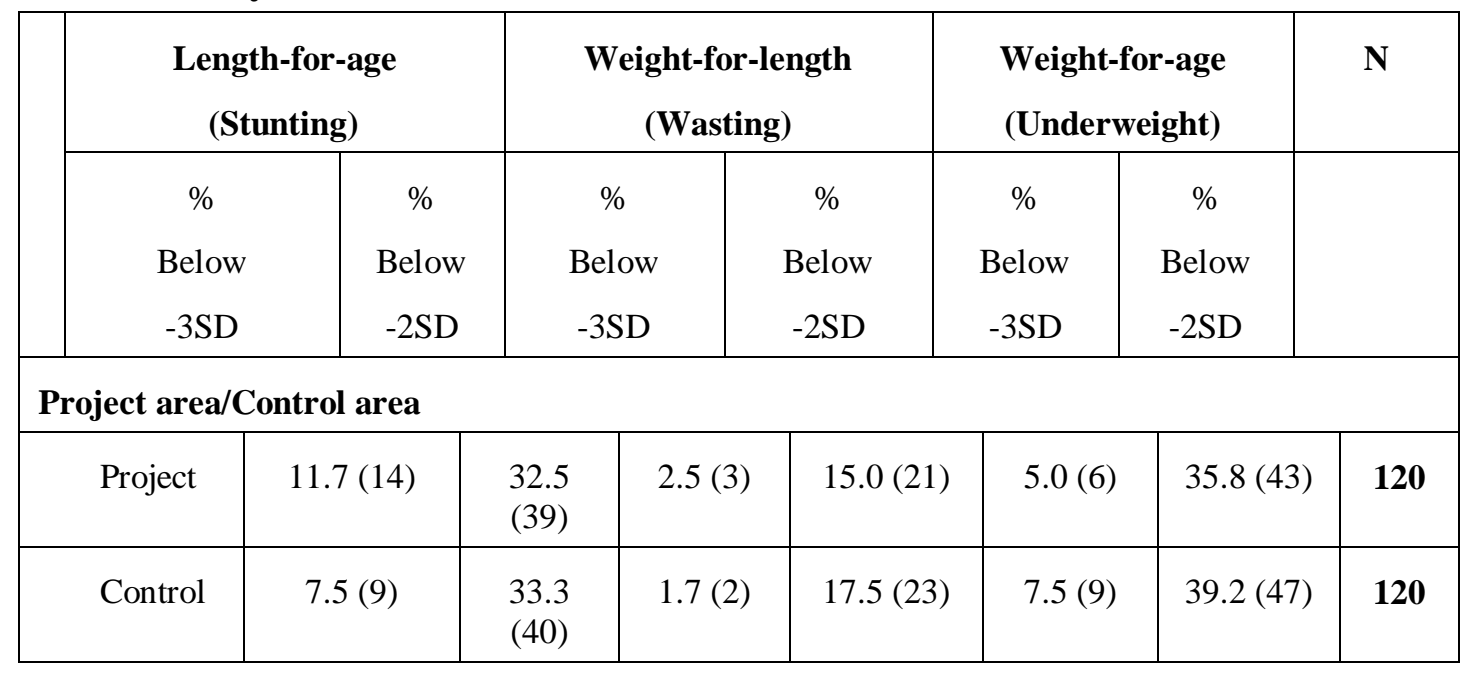

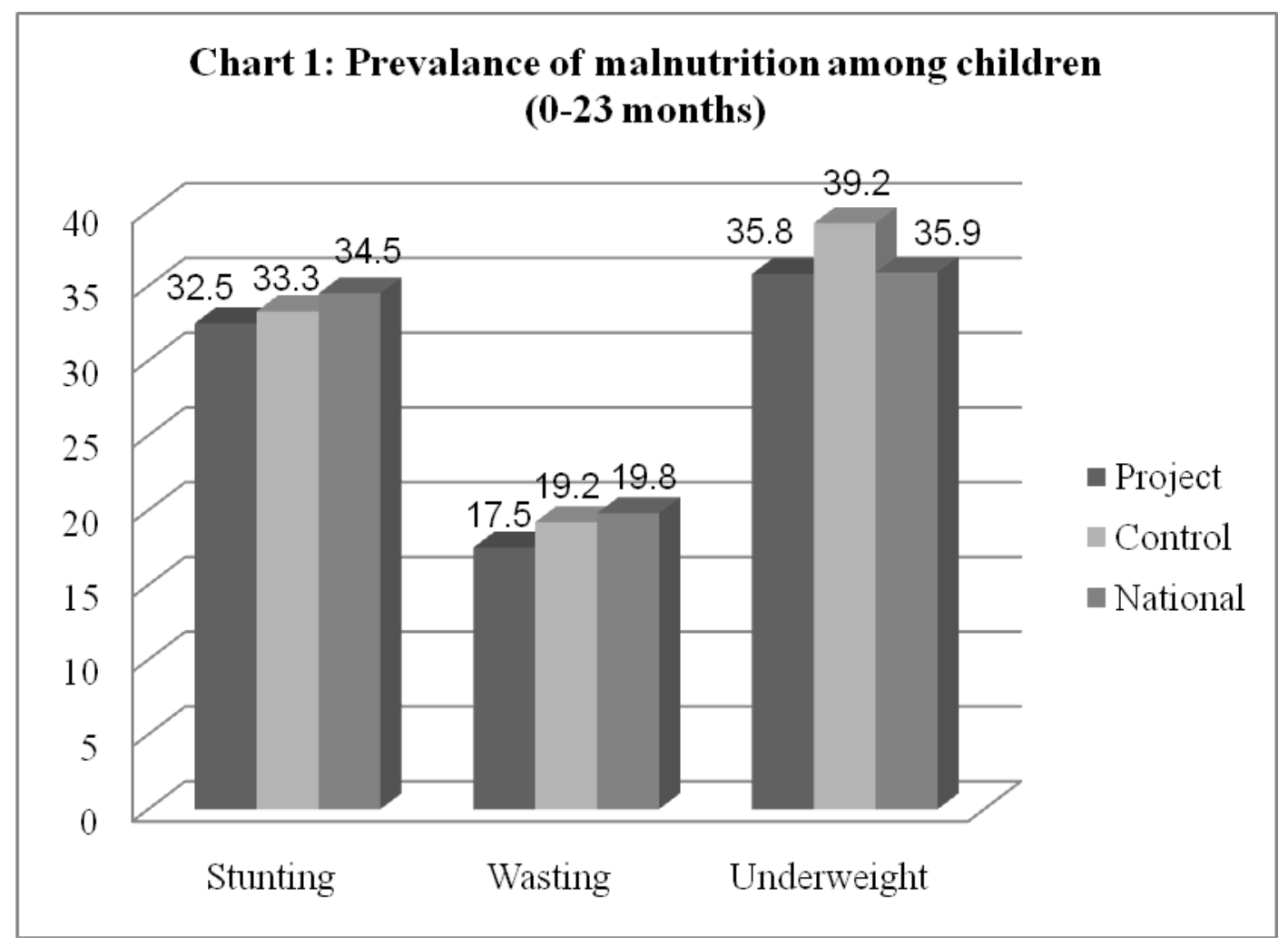


Rahman and Islam : Nutritional Status and Food Security

Table 3: Distribution of respondents by breastfeeding practices of children in the project and non-project area.

\begin{tabular}{|c|c|c|c|}
\hline Characteristics & $\begin{array}{c}\text { Project } \\
\text { area } \\
\mathrm{N}=120\end{array}$ & $\begin{array}{c}\text { Non- } \\
\text { project } \\
\text { area } \\
\mathrm{N}=120\end{array}$ & $\begin{array}{l}\text { Statistical } \\
\text { Significance }\end{array}$ \\
\hline Initiation of breastfeeding & & & $(\mathrm{P}>0.05)^{*}$ \\
\hline 24 hours after birth & $3.3(4)$ & $10.8(13)$ & \\
\hline Immediately after birth & $84.2(101)$ & $80.8(97)$ & \\
\hline Never breastfed & $4.2(5)$ & $6.7(8)$ & \\
\hline Colostrum feeding & & & $(\mathrm{P}>0.05)^{*}$ \\
\hline Yes & 95.8(115) & $86.7(104)$ & \\
\hline No & $4.2(5)$ & 13.3(16) & \\
\hline $\begin{array}{l}\text { Exclusive breastfeeding } \\
\text { (n, project }=92 ; \text { n, control=92) }\end{array}$ & & & $(\mathrm{P}<0.05)^{*}$ \\
\hline$<5$ months & $31.5(29)$ & 29.5(31) & \\
\hline 5-6 months & $48.9(45)$ & 37.1(39) & \\
\hline$>6$ months & 19.6(18) & 33.3(35) & \\
\hline $\begin{array}{l}\text { Introduction of complementary foods } \\
\text { (n, project=92; } n \text {, control=92) }\end{array}$ & & & $(\mathrm{P}<0.05)^{*}$ \\
\hline$<6$ months & $31.5(29)$ & $29.5(31)$ & \\
\hline At 6-7 months & $48.9(45)$ & 37.1(39) & \\
\hline$>7$ months & $19.6(18)$ & 33.3(35) & \\
\hline
\end{tabular}

Notes: ( $n$ is the total number of number of households having children over 6 months of age who are eligible for complementary feeding.) In bracketsfrequency *Chi-square test (p value<0.05) 
Bangladesh J. Nutr. Vol. 24-25 Dec 2011-2012

Table 4: Distribution of respondents by knowledge regarding breastfeeding of children in the project and non-project area.

\begin{tabular}{|c|c|c|c|}
\hline Characteristics & $\begin{array}{c}\text { Project } \\
\text { area } \\
\mathrm{N}=120\end{array}$ & $\begin{array}{c}\text { Non-project } \\
\text { area } \\
\mathbf{N}=120\end{array}$ & $\begin{array}{c}\text { Statistical } \\
\text { Significance }\end{array}$ \\
\hline Colostrum feeding & & & $(\mathrm{P}>0.05)^{*}$ \\
\hline Yes & 97.5 (117) & $94.2(113)$ & \\
\hline No & $0.8(1)$ & $2.5(3)$ & \\
\hline Don’t know & $1.7(2)$ & $3.3(4)$ & \\
\hline Exclusive breastfeeding & & & $(\mathrm{P}<0.01)^{*}$ \\
\hline$<5$ months & $3.3(4)$ & $6.7(8)$ & \\
\hline 5-6 months & $81.7(98)$ & $63.3(76)$ & \\
\hline$>6$ months & $7.5(9)$ & $17.5(21)$ & \\
\hline Don’t know & $7.5(9)$ & $12.5(15)$ & \\
\hline Sustained breastfeeding & & & $(\mathrm{P}<0.01)^{*}$ \\
\hline$<2$ years & $1.7(2)$ & $5.0(6)$ & \\
\hline Upto 2 years & $65.8(79)$ & $37.5(45)$ & \\
\hline$>2$ years & $30.0(36)$ & $57.5(69)$ & \\
\hline Don’t know & $2.5(3)$ & 0 & \\
\hline Introduction of complementary foods & & & $(\mathrm{P}<0.01)^{*}$ \\
\hline$<6$ months & $3.3(4)$ & $5.0(6)$ & \\
\hline At 6-7 months & $74.2(89)$ & $58.3(70)$ & \\
\hline$>7$ months & $15.0(18)$ & $14.2(17)$ & \\
\hline At insufficient breast milk & $1.7(2)$ & $10.8(13)$ & \\
\hline Don’t know & $5.8(7)$ & $11.7(14)$ & \\
\hline
\end{tabular}

Notes: In brackets- frequency $\quad *$ Chi-square test $\quad$ p value $<0.05$ 
Rahman and Islam : Nutritional Status and Food Security

Table 5: Distribution of households by reporting the consumption of foods of their children from specific food groups in the project and nonproject area.

\begin{tabular}{|c|c|c|c|}
\hline Characteristics & $\begin{array}{c}\text { Project area } \\
\qquad N^{1}=92\end{array}$ & $\begin{array}{c}\text { Non-project } \\
\text { area } \\
\mathbf{N}^{1}=105\end{array}$ & $\begin{array}{c}\text { Statistical } \\
\text { Significance }\end{array}$ \\
\hline Food Groups & & & $(\mathrm{P}>0.05)^{*}$ \\
\hline Grains, roots/tubers & $76.7(92)$ & $87.5(105)$ & \\
\hline Vitamin A rich plant foods & $28.3(34)$ & $7.5(9)$ & \\
\hline Other fruits or vegetables & $22.5(27)$ & $20.0(24)$ & \\
\hline Meat, poultry, fish & $22.5(27)$ & $17.5(21)$ & \\
\hline Eggs & $47.5(57)$ & $12.5(15)$ & \\
\hline Pules/legumes/nuts & $38.3(46)$ & $40.0(48)$ & \\
\hline Milk and milk products & $35.8(43)$ & $60.0(72)$ & \\
\hline Foods cooked in oils or fats & $46.7(56)$ & $32.3(34)$ & \\
\hline
\end{tabular}

Notes: (Figures in parentheses are frequency) $\left(\mathrm{N}^{1}\right.$ is the total number of number of households having children over 6 months of age who are eligible for complementary feeding.) ${ }^{*}$ Chi-square test ( $p$ value $<0.05$ ).

\section{References:}

1. Ahmed T, Ali M, Ullah MM, Chowdhury IA, Haque ME, Salam MA et al. Mortality in severely malnourished children with diarrhea and use of a standardized management protocol. Lancet 1999; 353:1919-22.

2. Murray CJ, Lopez AD. Global mortality, disability, and the contribution of risk factors: Global Burden of Disease Study. Lancet 1997; 349:1439-42.

3. United Nations Children's Fund. State of the world's children. New York, NY: United Nations Children's Fund, 2002. 103 p.

4. United Nations Children's Fund. State of the world's children. New York, NY: United Nations Children's Fund, 1998. 114 p.

5. Helen Keller International. Child and Maternal Nutrition Survey, 2005. p 62. 
Bangladesh J. Nutr. Vol. 24-25 Dec 2011-2012

6. National Institute Population Research and Training. Bangladesh Demographic and Health Survey, 2007, Dhaka, Bangladesh.

7. UNICEF. The Situation Analysis of Children and Women in Kenya, Nairobi. Ministry of Planning and National Development and UNICEF, Kenya Country Office 1998: 11-195.

8. Smith LC and L Haddad. Explaining Child Malnutrition in Developing Countries. A Cross country Analysis-Research Report (III). IFPRI. Washington DC 2000: 14.

9. Bangladesh. Ministry of Health and Family Welfare. National Nutrition Project Program Implementation Plan (NNP PIP). Dhaka, Bangladesh: Ministry of Heath and Family Welfare, 2004.

10. Chhibber, Ajay. "Project Performance Assessment Report Bangladesh Integrated Nutrition Project.” 13 June 2005. 